\title{
Quando biólogos olham para os bichos: caatinga, ecologia e zoologia entre vida, trabalho e morte
}

When biologists look at the animals: caatinga, ecology and zoology between life, work and death

\author{
Elizeu Pinheiro da Cruz ${ }^{*}$ \\ *Universidade do Estado da Bahia - Caetité, BA, Brasil \\ elizeuprof@gmail.com \\ https://orcid.org/0000-0003-1454-6832
}




\title{
Resumo
}

Em diálogo com análises etnográficas sobre as relações humano-animal, este texto apresenta desdobramentos de um estudo que, por meio da observação da rotina de laboratórios de ciências biológicas e de entrevistas com biólogos, rastreou trabalhos de descrição da biodiversidade permeados por tensões relacionadas à vida e à morte de animais de pesquisa do bioma caatinga. Argumenta-se que o jogo entre vida e morte que marca as relações que vinculam animais e os seus biólogos produz carreiras científicas em pesquisas que tomam como objeto os contornos do bioma caatinga como exclusivamente brasileiro, rico em diversidade biológica e ameaçado de extinção. Como desdobramento, as disciplinas científicas ecologia e zoologia são posicionadas como saberes de caatinga que versam sobre indicadores ambientais necessários à segurança dos não humanos em seus habitats.

Palavras-chave: animalidade; ciências biológicas; humanidade; laboratórios.

\begin{abstract}
Dialoguing with ethnographic analyzes on human-animal relations, this text presents developments from a study that tracked works of description of biodiversity which are permeated by tensions related to life and death of research animals of the caatinga biome, through observing the routine of life science labs and interviewing biologists. It is argued that the game between life and death that marks the relationships that bind animals and their biologists produces scientific careers in researches that take as their object the contours of the biome caatinga as exclusively Brazilian, rich in biological diversity and threatened with extinction. As unfolding, the scientific disciplines ecology and zoology are positioned as caatinga knowledge that deal with environmental indicators that are necessary for the safety of non-humans in their habitats.
\end{abstract}

Keywords: animality; biological sciences; humanization; laboratory. 


\section{Introdução}

Quando biólogos e animais encontram-se na caatinga em contextos de pesquisa, surgem descrições de diversidade e ocorrência ${ }^{1}$ de animais que passam a circular em comunidades de prática das ciências biológicas. Essas descrições, como produtos de modos de relação transespecíficas - aquelas nas quais “[...] mediante um encontro entre espécies distintas (um evento interespecífico), as próprias condições de existência e seus limites de contorno entram em relação" (Sá, 2013, p. 249) - sustentam a formulação da caatinga como bioma exclusivamente brasileiro (Nascimento; Ferreira; Moura, 2012/2013; Schober, 2002), contribuindo para marcar também o Brasil como diferença natural. Biólogos buscam conhecer animais, plantas e outros entes e, após relações de enredamentos múltiplos, os descrevem como espécies circunscritas e circunscritivas de áreas, podendo ser únicas, espécies jamais encontradas em outros lugares, as chamadas espécies endêmicas; ou espécies já catalogadas e que, após as suas descrições, são também nelas identificadas. Eles seguem os rastros dos não humanos: pegadas, cheiros, registros jornalísticos, relatos de humanos, marcas de hábitos alimentares e outros sinais deixados pelos animais nos diversos territórios em que transitam. Tais sinais permitem que biólogos encontrem e recrutem animais para participarem de pesquisas com a possibilidade de serem deslocados para laboratórios, onde são submetidos a protocolos específicos desses espaços.

Nesse cenário, enredamentos zoólogo-animal e ecólogo-animal, focos deste artigo, circunscrevem lugares, como distinções, em carreiras de biólogo em uma determinada instituição de ensino e/ou pesquisa. Durante o trabalho de campo que transita por este texto, realizado entre os anos de 2011 e 2016 em laboratórios de ciências biológicas da Universidade Estadual do Sudoeste da Bahia (Uesb), segui biólogos em suas práticas de pesquisa e os identifiquei relacionados a uma determinada ciência das ciências biológicas (botânica, ecologia e zoologia, por exemplo) e a um determinado animal, uma determinada planta ou outro ser vivo não humano de um determinado território ou de um

1 Biólogos diferenciam diversidade, que estaria relacionada às diferentes espécies, de ocorrência, que seria um marcador do registro de distribuição de espécies. Os registros de ocorrência de diferentes espécies, em um território, indicariam a sua diversidade. 
conjunto de territórios. Ao se referirem aos seus pares, os meus interlocutores mobilizavam enunciados que relacionavam biólogo, animal e território.

Antropólogos têm também se interessado por seguir animais (Osório, 2016; Sá, 2005, 2010; Segata, 2016, 2017; Souza, 2017a, 2017b; Süssekind, 2012), reconhecendo-os como agentes ativos que participam de enredos que os enlaçam aos humanos em experiências concretas e situantes de biotério, biomas, área de reserva e prevenção da dengue, entre outras. Animais e demais não humanos são agentes ativos que permitem, estimulam, interrompem e bloqueiam interações (Latour, 2012) para além da destreza intelectual e do que dizem sociólogos, antropólogos, epistemólogos (Sá, 2013), biólogos e outros humanos. Amparado nesse modo de compreender a agência dos animais não humanos, acompanhei trabalhos de biólogos para descrever experiências que os enlaçam aos animais da caatinga. A etnografia multiespécie (Kirksey; Helmreich, 2010; Süssekind, 2018; Segata, 2016, 2017; Tsing, 2015, 2019), modo de pesquisar (e escrever) escolhido para realização do estudo a que este texto faz referência, permitiu elaborar alguma intersecção de formas similares de trabalho de campo, do biólogo e do etnógrafo, ambas com muita observação, e das descrições delas resultantes.

Em muitos momentos da pesquisa, observei observadores de animais em seus ofícios, análogo ao que fez Sá (2005, 2010), para, nos termos da proposição de Vander Velden (2009), construir um diálogo comum entre distintos conjuntos de saberes sem hierarquização de narrativas, sejam elas das ciências biológicas ou das ciências sociais. Seguir biólogos em pesquisas nas quais caminhar e observar o entorno era condição indispensável ajudou-me a problematizar algumas equivalências entre os animais da caatinga e os seus biólogos. Nesse movimento, proponho, como objetivo deste texto, rastrear relações entre animais e biólogos em contextos de pesquisa ecológica e zoológica situados entre a vida e a morte, para descrever enredamentos humano-animal capazes de produzir carreiras científicas nas ciências biológicas que tomam como objeto de trabalho o bioma caatinga como exclusivamente brasileiro e elaboram saberes nas disciplinas científicas ecologia e zoologia como saberes de caatinga. ${ }^{2}$

2 A morte dos animais permite que os pesquisadores estudem os vivos e, nesse jogo ético de vida e morte, elaborem saberes que compõem os agenciamentos produtores das suas carreiras em um movimento situado, portanto circunscrito e circunscritivo, no escopo dos seus projetos que, $\rightarrow$ 


\section{Os laboratórios de zoologia e ecologia}

Para esboçar as tramas dos espaços descritos neste texto, mobilizo entrevistas (abertas e biográficas) e observações realizadas em três laboratórios, dois de zoologia e um de ecologia. As narrativas apresentadas pelos biólogos tematizaram os percursos de formação e trabalho que os vincularam aos animais de pesquisa. Frente a isso, e atento às reflexões de Merleau-Ponty (2012), tento aqui não explicar o trabalho do biólogo a partir da sua vida, mas entender que o seu labor diário define modos de ver e fazer especializados e constantemente elaborados, que retomam momentos anteriores da sua carreira e escolarização. Dessa forma, entendi que, ao falarem de si, os biólogos fariam aparecer os laboratórios a eles relacionados e os dispositivos que os vincularam aos animais não humanos.

Em um período significativo da pesquisa, observei e entrevistei biólogos que pesquisavam animais invertebrados e biólogos que pesquisavam plantas. Sentia-me reiteradamente provocado a negociar com os zoólogos curadores das coleções de animais constituídos de vértebras e medula espinhal do Laboratório de Zoologia II uma possibilidade de, ao menos, descrever aquela composição. Uma bióloga-zoóloga que hesitou em participar da pesquisa, mas com quem conversei em um momento de "pausa" no campo, de gravador desligado, recomendou-me outros zoólogos para entrevistar e, como coordenadora do espaço, me autorizou a descrever as suas coleções. Com o passar do tempo, tive a oportunidade de conversar algumas vezes com um biólogo sobre o porquê de ele aceitar participar da pesquisa e o porquê de possíveis recusas, suas e dos seus pares. Segundo ele, as recusas estariam relacionadas à exposição a pesquisas que poderiam julgá-los em critérios "frouxos", pouco ou nada "científicos" ou que, mesmo "rígidos" e "científicos", poderiam fazer recortes das suas falas

$\rightarrow$ sistematicamente, dialogam com os saberes já consolidados das suas disciplinas, ecologia e zoologia nesse caso. Portanto, não tenho aqui a pretensão de tratar do bioma caatinga fora do recorte dos meus interlocutores. Com isso, não estou necessariamente identificando-me com o ponto de vista "nativo", mas buscando, como sujeito formado também em ciências biológicas, um modo de reatualizar afetações (Favret-Saada, 2005) em cenas das ciências biológicas urdidas pela circularidade de saberes (sobre o bioma caatinga e sobre o matar e o morrer que tornam possível a formulação de enunciados que sustentam a sua exclusividade brasileira) que permitiam aos biólogos a elaboração de pesquisas, partindo de pressuposições ancoradas nas literaturas consolidadas das suas disciplinas. 
e das suas histórias que eles não tinham interesse em tonar públicas. Como os "nativos" de Sá (2005), os meus interlocutores não estavam acostumados a serem pesquisados, mas a pesquisar. Eu estava realmente me importando com isso e comecei a hesitar diante de critérios mobilizados por mim em momentos iniciais da pesquisa. No início do trabalho de campo, dizia aos interlocutores que fazia uma história da ciência do tempo presente. Após alguns anos, passei a chamar (e fazer) o trabalho de etnografia, o que me deixou mais confortável com o tipo de engajamento que eu desejava. No entanto, passei a vivenciar um mal-estar: não queria ocultar o nome dos meus interlocutores, conforme identificava em algumas etnografias, e eles concordaram. A partir da reflexão de Despret (2011d, p. 16), entendi, retrospectivamente, que a rejeição do anonimato dos biólogos estaria ancorada na negação da instauração de um segredo "o efeito sem nome", que deixa as pessoas desinteressantes e pouco interessadas. Nesse deslocamento, para ser mais cuidadoso com as demandas dos interlocutores e com as minhas, propus aos biólogos o envio dos manuscritos dos textos a serem publicados após a conclusão da tese. Decidi mantê-los por perto e tive devolutivas interessantes do "efeito com nome".

Monitores, estagiários e pesquisadores de iniciação científica do Laboratório de Zoologia II apresentaram-me os animais e as suas coleções, situando quem seriam os seus biólogos e, quando possível, como (condição) e onde (lugar) foram recrutados. Eles reafirmavam sistematicamente que a morte de um animal só acontece em situações de extrema necessidade. Biólogos matam animais e os transformam em peças de coleções, chamadas de coleções de referência, com vistas a utilizá-los em pesquisas, aulas e exposições. Naquele espaço, identifiquei uma grande quantidade de animais, dentre os quais se destacavam exuberantes pássaros taxidermizados ${ }^{3}$ e fixados sobre bases como fragmentos de tronco de árvores e placas de isopor. Tentava-se ali encenar um pouco do habitat natural dos animais, indicar a suas naturezas/animalidades e, quando oportuno, compará-los com a animalidade dos humanos.

No Laboratório de Zoologia I, situado no mesmo corredor, observei espécimes de invertebrados e vertebrados. As correspondências entre animais para aula e animais para pesquisa não eram necessariamente equivalentes nos

3 Taxidermia é uma técnica de tratamento da pele de animais que garante a preservação de algumas caraterísticas do animal vivo no animal morto. 
dois laboratórios. No Laboratório de Zoologia I, por exemplo, espaço onde se desenvolviam aulas práticas relacionadas aos grupos de animais invertebrados, havia zoólogos pesquisando vertebrados (peixes e roedores). Os professores daquele espaço foram recrutados pela Uesb para lecionar componentes curriculares relacionados a um determinado grupo de animais, mas, devido às suas trajetórias, pesquisavam, na ocasião, animais de outros grupos taxonômicos. No laboratório, conversei com uma bióloga que trabalhava com peixes, que também atuava no Laboratório de Zoologia II, e um biólogo que trabalhava com roedores. Quando perguntei a um deles sobre qual era atuação daquele laboratório na conjuntura das ciências biológicas locais, ele disse que, para responder a minha questão, "olhava para os bichos"4 e concluía ser um laboratório de invertebrados apenas "no sentido da didática", pois os roedores e os peixes inventariados em suas coleções sinalizavam para as investidas em pesquisas sobre/com animais vertebrados.

Ao sair do Laboratório de Zoologia I, atravessar um módulo de aula teórica e a prefeitura do campus, é possível visualizar o Módulo Eugênio Borges de Jesus, ${ }^{5}$ onde está situado o Laboratório de Biodiversidade do Semiárido (o Labisa). Professores que atuavam nos dois laboratórios de zoologia e em outros laboratórios de botânica e ecologia também desenvolviam ações relacionadas ao Labisa.

A setorização em duas seções era algo comum em todos os laboratórios: uma delas era destinada à execução de aulas e protocolos de pesquisa e a outra era subdividida em pequenos gabinetes de trabalho dos pesquisadores. O espaço de atividades práticas ocupava uma porção maior do laboratório e, eventualmente, comportava gabinetes de estudantes e pesquisadores. Adentremos aos laboratórios!

4 Os biólogos usaram, frequentemente, a palavra "bicho" para fazer referência aos animais não humanos.

5 Eugênio Borges de Jesus foi um docente que integrou o grupo de fundadores do Curso de Licenciatura Curta em Ciências da Faculdade de Formação de Professores de Vitória da Conquista (FFP/VCA) na década de 1970. A FFP/VCA foi agrupada com outras faculdades/escolas das cidades de Jequié e Itapetinga para dar origem à Universidade do Sudoeste (US) em 1980, posteriormente, na segunda metade da década de 1980, reformulada em Universidade Estadual do Sudoeste da Bahia (Uesb). 


\section{Roedores-com-biólogos}

Em uma bancada no centro do Laboratório de Zoologia I, o biólogo-zoólogo Gilson Evaristo Iack Ximenes dispôs alguns roedores oriundos de distintos territórios baianos, descrevendo as pesquisas a eles relacionadas e as questões que poderiam interrogá-los. Em todo o seu percurso formativo e profissional, Gilson tem atuado em pesquisas relacionadas à taxonomia e sistemática de mamíferos. Ele se define como um "vertebradólogo" identificado com museus de zoologia, locais onde se trabalha com coleções de animais, examinando ossos, musculatura e morfologia externa para elaborar compreensões acerca dos vínculos evolutivos entre os animais. Pesquisadores que atuam em museus necessitam também ir a campo para aumentar a amostra da diversidade dos grupos de animais que pesquisam.

Após a conclusão do seu doutorado, Gilson se mudou de São Paulo para a Bahia, onde passou a desenvolver projetos em áreas ${ }^{6}$ de caatinga. ${ }^{7}$ Segundo Gilson, coletar mamífero exige condições específicas como a montagem de um laboratório em campo para matar os bichos e iniciar o trabalho de taxidermia, ações que exigem um tempo de, no mínimo, oito dias para serem realizadas. No primeiro dia, colocam-se as armadilhas; no segundo, raramente os bichos entram nas armadilhas, porque elas ainda não se "aclimataram" (elas precisam perder o cheiro); nos terceiro, quarto e quinto dias, os bichos visitam as armadilhas; e, no sexto dia, retiram-se as armadilhas e demais equipamentos para retornar ao laboratório no sétimo dia.

Os espaços do Laboratório de Zoologia I são ocupados por coleções e equipamentos, sem oferecer condições adequadas para que as coleções de pesquisa possam ser utilizadas sem prejuízo dos usos dos espaços ou dos materiais. Conheci parte da coleção de roedores do laboratório. Aqueles animais, coletados em ações do Programa de Pesquisa em Biodiversidade do Semiárido ${ }^{8}$

6 Estudos em territórios como florestas e parques foram chamados pelos meus interlocutores de "estudos de área".

7 As categorias "semiárido", "sertão", "caatinga" e "região sudoeste" apareceram sobrepostas nas entrevistas, sem assumirem, necessariamente, relações de sinonímia.

8 O Programa de Pesquisa em Biodiversidade (PPBio) foi criado pelo governo federal em 2004, e se estrutura em três componentes: inventários, coleções e temáticas da biodiversidade brasileira. 
e transformados em peça de coleção esperavam por espaços adequados para os fins de pesquisa, ausentes na instituição à ocasião. As condições adequadas, indicadas pelos biólogos, estariam relacionadas à existência de espaços exclusivos e isolados para fins de tratamento de materiais biológicos como carcaças e peles. A falta de espaço dificultava o adequado acondicionamento e o uso do material consoantes com um museu de zoologia. Entretanto, a manutenção daqueles roedores no Laboratório de Zoologia I oferecia possibilidades de pesquisas a professores e estudantes.

Para matar um roedor em campo, os biólogos e seus orientandos colocam o animal sobre uma "cama" de algodão encharcada de clorofórmio," usado para causar morte súbita como diminuição do sofrimento do animal devido à sua propriedade anestésica. Após essa primeira etapa, inicia-se um momento de pausa para auscultar os batimentos cardíacos do bicho, pois há sempre a possibilidade de reanimação. Passado esse tempo, caso ressurjam os batimentos cardíacos, o trabalho não segue para a próxima etapa; ou, quando a morte é confirmada, abre-se o corpo do animal com um bisturi na altura da região abdominal para a retirada das vísceras. As carcaças resultantes, com ossos e resíduos da musculatura, são colocadas em um recipiente, onde Gilson e seus orientandos acrescentam larvas de besouros, que, após a eclosão, tornam-se animais capazes de comer a musculatura dos roedores; eles "fazem a limpeza dos ossos" para a sequência ao trabalho de pesquisa. A retirada da musculatura dos ossos pode gerar danos, sendo necessária uma cuidadosa perícia (mãos e besouros habilidosos) para a manutenção do esqueleto do animal. Procedimentos que envolvem a utilização de produtos químicos podem enfraquecer os ossos, elementos indispensáveis ao trabalho de taxonomia. "Os besouros comem tudo e fica limpinho. Se as vísceras não forem logo retiradas, a carcaça apodrece e se torna inviável", disse Gilson. O processo de transformação do animal vivo em peça de coleção, ${ }^{10}$ chamado pelos biólogos de "tratamento da carcaça", habilitam-no a integrar

9 O uso do clorofórmio é controverso entre pesquisadores. Segundo Gilson, há profissionais de saúde que não aprovam o uso do clorofórmio porque esta substância causaria sufocação nos animais, aumentando o sofrimento. Para enfrentar a argumentação dos que se posicionam contrários ao uso do clorofórmio, ele dialogou com uma anestesiologista, que se mostrou favorável ao seu uso.

10 Entidade distinta em relação ao animal vivo, sem, no entanto, ser menos real. 
uma coleção. Cumpridas as etapas de coleta e limpeza do material, uma coleção de referência é montada e as descrições dos animais são iniciadas.

Descola (1998, p. 29) apresenta uma imagem sobre a morte de animais entre povos amazônicos que parece estabelecer alguma regularidade de sentido com a morte entre os biólogos:

A morte dos animais e sua preparação não é dissimulada em recintos afastados da visão dos profanos, como ocorre entre nós atualmente, e todo mundo na Amazônia é familiarizado desde a mais tenra idade com aqueles corpos ainda quentes que se vão esfolar, estripar e cortar para cozinhar. Graças às intermináveis histórias de caça que os homens gostam de contar, todo mundo também sabe qual foi o comportamento do animal antes de morrer, o medo, a tentativa de fuga abortada, o sofrimento, as manifestações de aflição dos seus companheiros. Em suma, ninguém pode ignorar de que maneira um ser vivo se torna comida.

Biólogos iniciam as suas formações em cursos de ciências biológicas assistindo à morte de animais e progridem, caso decidam pesquisar (com) animais em suas carreiras, para assumir o ato de matar justamente aqueles animais sobre os quais estudam sistematicamente o comportamento, a fisiologia e a morfologia dos seus corpos. Também entre eles não há espaço para dissimulação. Áreas de coleta e espaços físicos de laboratórios encontram-se em práticas dos seus atores nas situações de morte e ninguém ignora como um animal se torna parte de uma coleção.

Para os biólogos, as áreas são definidas a partir das diversidades de vida animal e vegetal que as constitui. Eles descrevem os seres vivos não humanos que as habitam e as definem comparando-as com outros territórios, próximos ou distantes. Em áreas bem amostradas, onde muitas pesquisas já foram realizadas, as chances de encontrar novas espécies são menores e o esforço é direcionado para registros de ocorrência das espécies. Quando um biólogo vai a um ambiente nada ou pouco amostrado, as chances de encontrar "espécies novas" aumentam. A depender do que se define como objeto de pesquisa, tomando como referência apontamentos pré-construídos sobre um determinado território, as possibilidades de encontrar novas espécies são maiores ou menores, o que justifica a retomada das coleções dos museus de zoologia e dos textos das comunidades de prática da taxonomia biológica, que reúnem descrições 
de espécimes e espécies de diversos territórios. Há, ainda, a possibilidade de investigar territórios e redescrever seus não humanos, inclusive como modo de identificar os equívocos das descrições anteriores.

Gilson trabalhou com uma linhagem de roedores de maior incidência na Amazônia, mas que também teve registradas ocorrências de seus espécimes em Minhas Gerais e Bahia. Dentro da linhagem, no entanto, há um gênero considerado eminentemente baiano, o gênero Callistomys (descrito por Emmons e Vucetich em 1998). Nesse gênero, há uma espécie que foi encontrada apenas na Bahia, a espécie Callistomys pictus, entre os anos 1943-1946, ficando "desaparecida" do olhar humano por 50 anos, até ser reencontrada na década de 1980 em uma cena de atropelamento entre as cidades de Ilhéus e Itabuna, Bahia. "Bicho lindíssimo, ele é o urso panda dos ratos", asseverou Gilson sobre a espécie, que é popularmente conhecida como saruê-beiju ou rato-do-cacau. Desde então, Callistomys pictus apareceu algumas vezes. Antes de ser incluída no gênero Callistomys, os indivíduos que hoje compõem a espécie Callistomys pictus foram incluídos em outros gêneros e, por isso, a distância temporal entre o registro em Minas Gerais, em 1938, e a descrição do gênero Callistomys, em 1998. O trabalho de Gilson e de outros biólogos com a espécie resultou em sua inclusão no Livro vermelho da fauna brasileira ameaçada de extinção (Instituto Chico Mendes de Conservação da Biodiversidade, 2018).

\section{Peixes-com-biólogos}

Os peixes que habitam os laboratórios de zoologia da Uesb atuam vinculados à bióloga Flávia Borges Santos em trabalhos de descrição da ictiofauna de territórios da Bahia. Flávia especializou seu modo de ver a biodiversidade nos seus cursos de graduação, mestrado e doutorado para perceber peixes do mar, tornando-se bióloga-zoóloga-ictióloga. Como Gilson, Flávia mudou-se de São Paulo, onde realizou a sua formação universitária, para a Bahia e integrou ao corpo docente da Uesb. Era, na ocasião da minha pesquisa, a única pesquisadora de peixes do coletivo de zoólogos de que fazia parte. Seu deslocamento regional, do sudeste para uma cidade do interior do nordeste do Brasil, distanciou-a da costa brasileira, do mar, o que provocou a diversificação dos seus interesses de pesquisa para incluir neles os grupos de peixes que vivem em 
ecossistemas de rios, barragens, riachos e outros corpos d’água da região onde passou a atuar. Uma porção dos peixes coletados é levada para o laboratório e organizada em coleções de referência, aquelas constituídas por animais mortos.

Para ela, o trabalho de identificação dos peixes descreve a "abundante biodiversidade" destes não humanos em uma corrida contra a constante ameaça de destruição de "uma biodiversidade que ainda não conhece". Uma das ações que ilustra a ameaça à biodiversidade regional foi a introdução de espécies de peixes alóctones (que não são originárias da região, que vêm de fora) na Barragem de Anagé, Bahia, munícipio que dista cerca de 50 quilômetros de Vitória da Conquista, onde situa-se um dos campi da Uesb. Na barragem, foram introduzidas, não se sabe por quem, espécies de piranha e tucunaré provenientes de Minas Gerais e do Pantanal, que apresentaram comportamento classificado pelos biólogos como "agressivo". Essas piranhas passaram a competir com as espécies autóctones (aquelas que habitam o seu local de origem), que, segundo os biólogos, podem deixar de existir antes mesmo do seu "descobrimento" pelas ciências biológicas. "A descrição de espécies novas que ocorrem aqui [na região] é muito importante, porque é um ambiente, esses riachos do semiárido, muito pouco conhecido", destacou Flávia. Piranhas e tucunarés agressivos têm potencial para produzir desaparecimentos de determinados peixes (ocorrência) ou mesmo o total desparecimento de espécies nativas (diversidade) ainda não descritas pelos biólogos. Devido à existência de poucos ictiólogos na Bahia, haveria muitas possibilidades para descrições de espécies novas e registro de ocorrência das espécies já catalogadas, mas desconhecidas em territórios baianos:

Vira e mexe, na Bahia, você joga uma tarrafa e tira uma piaba ou um bagre novo. Essa história de que caatinga não tem diversidade é o maior papo furado. É papo do pessoal que não conhece a caatinga, porque tem muita coisa para estudar, muita, muita.

As redes das (e de) pesquisas de Flávia negam a ligação entre caatinga e pobreza por meio de registro de diversidade e ocorrência de peixes. A bióloga-zoóloga-ictióloga indica (e se contrapõe a) a existência de descrições produzidas por biólogos de instituições de pesquisa de outros estados brasileiros, biólogos de fora, que tomam como referência indicadores de diversidade e ocorrência 
produzidos para reafirmar a caatinga como bioma pobre em biodiversidade. Dispositivos de pesquisa que poderiam indicar a riqueza da caatinga seriam mobilizados pelos biólogos que se deslocam para habitar nas áreas investigados ou em suas cercanias. Em seu trabalho, territórios se tornam caatinga em laboratórios (Latour, 2017) como práticas que conectam os locais onde os animais são coletados e os espaços físicos institucionais da Uesb por meio de um trabalho rotineiro que exige um constante deslocamento dos biólogos, um incessante ir e vir.

\section{Morcegos-com-biólogos}

Calendário lunar, GPS, lanternas, redes e outros objetos acompanham o biólogo-ecólogo Raymundo José Sá Neto e estudantes de graduação relacionados ao Labisa em expedições por territórios da Bahia, onde é possível recrutar morcegos para a realização de pesquisas. As coletas de morcegos acontecem preferencialmente em noites de lua nova. Nelas, os morcegos reduzem o uso de espaços abertos e restringem as atividades de busca de alimento (o forrageio), tornando-se disponíveis para o encontro com os biólogos. Para não comprometer as aulas dos cursos de graduação, as expedições acontecem aos finais de semana. Cada expedição é composta por, no mínimo, duas pessoas para viabilizar a montagem da rede de coleta. $\mathrm{O}$ trabalho dos pesquisadores depende do trabalho dos animais (do forrageio). Os animais capturados pelas redes são marcados com um colar e devolvidos para o trabalho noturno de forrageio. Porém, alguns deles são mortos, tratados e depositados em coleções. Segundo Raymundo, estudantes em processo de iniciação em coletas matam muitos animais porque não sabem identificá-los vivos em campo. Os bichos precisam morrer para o trabalho de taxonomia acontecer no laboratório, para onde são levados.

Como Gilson, Raymundo também se recusou a chamar a morte dos animais de sacrifício e destacou o seu esforço de pesquisa para matar o mínimo possível. Segata (2016), ao acompanhar o caso da cachorra Belinha em um pet shop, foi reprovado por um veterinário quando chamou a morte dos animais de sacrifício, seu interlocutor preferia o termo "eutanásia" para distanciar daquilo que ele entendia como morte inútil (gratuita e banalizada), que seria o "sacrifício", 
situando-a no campo da técnica. ${ }^{11}$ Entre os biólogos, há também a tentativa de situar a morte dos animais no campo da técnica, sem, no entanto, adjetivar o sacrifício de animais em religiões com marcadores que remetem a inutilidade.

Sacrifício em religiões e morte em pesquisa de biólogos assumiram diferentes sentidos no campo, cada um desses modos de matar foi reconhecido como importante, ainda que envolvesse sofrimento animal. Então, passei a prestar atenção no entendimento que os meus interlocutores tinham sobre o sofrimento dos animais de pesquisa e como o mobilizam para compreender a morte dos animais. Nesse sentido, faço coro com Osório (2016, p. 51): "Embora crueldade, violência, sofrimento e maus-tratos não sejam sinônimos, são categorias que permitem a introdução a um universo de significados concernente a certas relações humano-animal e ao campo ocidental moderno de reflexões sobre elas." Entre os biólogos, a morte de animais é entendida como um sofrimento útil e necessário, não apenas para os humanos que dependem da morte para trabalhar (e fazer ciências), mas sobretudo para proteger as vidas dos demais espécimes da espécie que o animal morto representa e os seus entornos.

Em sua pesquisa de doutorado, Raymundo descreveu distribuição e abundância das espécies de morcegos e as suas comunidades (ecologia de comunidades) em uma grande área de caatinga, na planície do rio São Francisco. Ele disse que trabalhava com ecologia de comunidades utilizando morcegos devido à alta diversidade e facilidade na identificação do animal, o que lhe permitia conhecer a riqueza de espécies de uma determinada área de estudo e compará-las com outras áreas. Destruição e fragmentação de um território podem afetar as comunidades de morcegos, interferem na diversidade de espécies. Quando o indaguei sobre endemismo entre os morcegos, ele afirmou:

Eu brinco que tudo que era endêmico na época da minha graduação caiu, todas as espécies de morcegos que eram endêmicas na época de minha graduação caíram, porque, na verdade, você não tinha endemismo, você tinha era falta de

11 Isso parece não ser um consenso em outros contextos de pesquisa: Souza (2017a) e seus interlocutores de um biotério, por exemplo, usaram os termos "sacrifício" e "eutanásia" para fazer referência à morte dos camundongos que participavam de uma pesquisa sobre doença de Chagas. Gaspar (2018), em sua pesquisa em contextos de cuidados veterinários, identificou o uso do termo "eutanásia" entre veterinários e proprietários de animais, ainda que, para alguns destes últimos, houvesse uma reticência em usar o termo "eutanásia". 
estudo. Então você tinha várias espécies que eram do Sudeste, porque em São Paulo se estudava mais. Aí, quando se começou a se trabalhar mais na região Nordeste, você descobria [aqui] várias dessas espécies chamadas endêmicas.

Para Raymundo, as espécies exclusivas de um território seriam aquelas recentemente descritas; estudos posteriores poderiam indicar suas ocorrências em outros locais, abrindo um campo de investigação. Essa formulação faz ressoar falas ditas por outros biólogos durante todo o período da minha estadia no campo. Elas problematizavam os significados sobre a correspondência entre endemismos e territórios isolados geograficamente, com condições climáticas e geológicas específicas que participam dos processos de seleção natural das espécies e oferecem condições para surgimento de espécies exclusivas, no que concerne às suas ações de pesquisa e às descrições de plantas, animais e outros seres dos diversos territórios delas resultantes. Esses territórios seriam, para os meus interlocutores, isolados também dos olhares e das ações dos biólogos, das ciências biológicas e das suas taxonomias. Neles, os taxonomistas têm mais chances de encontrar endemismos, inclusive em contextos marcados por riscos e desastres. Tal isolamento apareceu no campo como apontamento do saber local (ecologias e zoologias locais) produzido por meus interlocutores que se contrapõe às narrativas sobre biodiversidade brasileira que fazem aparecer o bioma caatinga como pobre em biodiversidade na construção da ideia de nação rica em biodiversidade. Descrições apressadas, resultados de trabalhos pontuais em territórios da caatinga, ao produzir constructos teóricos como um molde narrativo (Despret, 2016) que oculta a riqueza desse bioma e atualiza preconceitos fundacionais do Brasil, são também desastrosas.

\section{Insetos-com-biólogos}

Biólogos e insetos do Labisa foram pioneiros em pesquisas de territórios da caatinga. As investigações surgiram em resposta a demandas de elaboração de políticas de manejo da biodiversidade apresentadas por munícipios baianos. Os biólogos conhecem as áreas de pesquisa caminhando por florestas e outras matas em aulas de campo para turmas de graduação e pós-graduação. Uma delas foi à Cachoeira do Buracão, localizada no Parque Natural Municipal do 
Espalhado, Unidade de Conservação (UC) ${ }^{12}$ do município de Ibicoara, Bahia. A prefeitura de Ibicoara buscou, junto ao Curso de Ciências Biológicas da Uesb, uma parceria para a elaboração de um plano de manejo para o parque que estabelecesse o seu zoneamento e as normas de uso da sua biodiversidade, um tipo de dossiê com as necessárias descrições do território em termos da sua geologia, da sua fauna e da sua flora. Os planos de manejo reúnem apontamentos produzidos por uma equipe multidisciplinar, nas quais biólogos, plantas, animais e outros não humanos são importantes atores do processo de elaboração dos indicadores ambientais para uso sustentável de áreas a serem manejadas. Os biólogos aceitaram a proposta e as instituições envolvidas, prefeitura de Ibicoara e Uesb, firmaram um convênio, tendo a professora Raquel Perez Maluf como a representante da Uesb, dos biólogos. Ao referir-se ao local, Raquel considerou:

É um patrimônio que o município percebeu que ele tinha que ser preservado. [...] eles queriam criar uma regulamentação para visitação do parque. Como é que você estabelece isso? Tentando conhecer o parque para ver o que haveria de importante para ser preservado e o que poderia ser diagnosticado em termos de paisagem com importância de preservação.

Com o convênio, o Curso de Ciências Biológicas da Uesb de Vitória da Conquista "ganhou" uma área de estudo que se tornou "carro-chefe do Labisa", onde os estudantes experimentaram o trabalho de pesquisa de campo orientados por seus professores. Os envolvidos nas pesquisas que contribuíram para a elaboração do plano de manjo decidiram fazer quatro "campanhas"13 para a produção do diagnóstico ambiental: duas na estação seca e duas na estação chuvosa. As expedições da equipe do Labisa acontecem, geralmente, durante os sete dias de uma semana: são necessários dois dias para a viagem (ida e volta), em que são realizadas montagem e desmontagem dos equipamentos, e cinco dias para realização das coletas, a fim de contemplar

12 As unidades de conservação são regulamentadas pela lei federal $\mathrm{n}^{\circ} 9.985$, de 18 de julho de 2000 , que instituiu o Sistema Nacional de Unidades de Conservação da Natureza (Brasil, 2000).

13 Os biólogos usavam, nas entrevistas, as palavras "campanhas", "coletas" e "expedições" como sinônimas. 
diferentes métodos de pesquisa. A Floresta Nacional Contendas do Sincorá ofereceu "uma base de dados", conforme definiu Raquel, e teve seu plano de manejo finalizado em 2006.

Durante as minhas observações e diálogos no Labisa, retomei as questões relacionadas aos endemismos de caatinga para descrever uma diferença entre os trabalhos nele desenvolvidos e os trabalhos de taxonomia desenvolvidos no Laboratório de Zoologia I. Eles sinalizam distintos modos de ver e fazer, que, longe de se antagonizarem, diversificam as compreensões sobre a biodiversidade local. Raquel, que é de origem espanhola e residente no Brasil desde criança, atua em questões relacionadas a comportamento animal, inventário faunístico, aprendizagem olfativa e complexo planta-animal-hospedeiros-inimigos naturais. Essas temáticas refletem a sua formação em entomologia e em biologia do comportamento, mestrado (desenvolvido em Minas Gerais) e doutorado (desenvolvido em Paris), respectivamente. Ainda que questões de taxonomias sejam importantes para o seu trabalho, ela é interessada em comportamentos de abelhas e vespas como possibilidades de compreensão dos animais que participam das suas pesquisas, e não apenas nos atributos morfológicos definidores de táxons. Ao situar os animais em campos de relações específicos (nichos e habitats), pesquisas sobre comportamento dos animais contribuem para sustentar que qualquer espécime pode ser assumido como inovação em campos de relações específicos (Ingold, 1995, 2015).

Raquel relatou, de maneira recorrente, o seu interesse em atuar na divulgação da ciência para as pessoas dos territórios onde realiza os trabalhos de pesquisa. Em sua opinião, atividades como congressos de pesquisadores promovidos pela universidade não alcançam o público que vive nas áreas descritas, pois são pouco efetivos para que os seus moradores tenham acesso a um conjunto de saberes sobre os animais que permite "uma apropriação do território". Ela encoraja os seus orientandos a enviarem os trabalhos realizados para as prefeituras e outras instituições das respectivas áreas, visando aos possíveis usos dos resultados das pesquisas na elaboração das políticas locais. No entanto, a sua rotina de trabalho em cursos de graduação e de pós-graduação dificulta o desenvolvimento das ações de divulgação. Para se manterem como docentes de pós-graduação, os biólogos necessitam produzir textos (preferencialmente em inglês) que são direcionados às revistas especializadas. Esse tipo de exigência drena esforços e tempo, o que dificulta ações de divulgação para as 
comunidades locais, onde as pesquisas são realizadas. Sugiro que esse conhecimento retorna, em um grande lapso temporal, nos livros didáticos escolares, depois de circular, ser traduzido e legitimado pelas comunidades dos biólogos e dos elaboradores de tais compêndios.

Como seus pares, Raquel denunciou as descrições pontuais produzidas por pesquisadores de fora da região acerca de territórios de caatinga. Para ela, trata-se de resultados de trabalhos que focam em áreas mais degradadas, "com mais intervenção humana", e não investigam as áreas preservadas em períodos de seca e chuva para demonstrar as drásticas alterações da paisagem. Seriam, assim, descrições parciais e interessadas em reafirmar apontamentos prévios e equivocados sobre a caatinga e o semiárido como áreas de pouca água e pobres em biodiversidade. Em contraposição, pesquisadores no local, fazendo um trabalho rotineiro e permanente, contribuiriam para a elaboração de descrições que contemplariam as diferentes áreas, preservadas e não preservadas, e as mudanças na paisagem em períodos de chuva e seca. Raquel considerou que "a diversidade da caatinga chuvosa pouca gente conhece, porque ela é muito efêmera. Se você está ali todo dia, você convive com isso e tem oportunidade de ampliar esse conhecimento da caatinga."

Esses apontamentos permitiram interrogar a própria formulação do conceito de biodiversidade, olhando mais atentamente ao comportamento de animais e plantas.

Você tem uma flexibilidade comportamental, fisiológica, que é incomparável. Uma espécie que consegue sobreviver na caatinga, ela vai ter uma flexibilidade comportamental, uma estratégia fisiológica muito mais diversa. Então diversidade é o quê? [Pausa]. Quando você começa a conhecer essa estrutura da caatinga, ela começa a ficar diferenciada e a paisagem da caatinga não é só essa paisagem de seca, que é a mais disseminada, porque, claro, é a que mais persevera. Mas quando chove na caatinga, aí a vida está ali pulsante. Há espécies que conseguem tolerar essa falta de água, elas ficam ali em stand-by, esperando as condições melhorarem. Você tem uma explosão de vida na caatinga quando você tem água na caatinga. Então eu acho que a gente contribui pra isso e para saber assim: não é por que tem menos espécies que ela é pobre. Na verdade, você tem uma riqueza fisiológica de estratégias de adaptações que não tem paralelo com o que você encontra na mata atlântica ou nas florestas mais úmidas. 
O entendimento da biodiversidade da caatinga, e de outros biomas, abarcaria questões de adaptação, que envolvem distribuição e permanência dos animais, os seus contextos de relação, e não apenas endemismos. Biólogos da Uesb ampliariam o conhecimento sobre o local (a caatinga) porque o habitam, fazendo aparecer dispositivos de pesquisa que ativam as alteridades animais locais que, por sua vez, se revelam diversas em comportamentos, em estratégias de adaptação, que fazem aparecer o bioma caatinga como riqueza natural.

\section{Morte-vida em afetos-trabalhos}

Se, por um lado, deslocamentos de animais de uma região para outra podem ser compreendidos pelos biólogos como condição de possibilidade de conflitos entres os espécimes introduzidos e os espécimes dos locais receptores devido ao surgimento de relações ecológicas que propiciam a atuação agressiva dos alóctones ou dos autóctones nos ecossistemas receptores, com consequência no desaparecimento de espécies, por outro lado, deslocamentos dos biólogos, nos casos relacionados ao campo de pesquisa retomado por este texto, deslocam foco e escopo dos seus interesses (Gilson-com-roedores), orientam na redefinição de questões de pesquisa e contribuem para: produzir saberes que reelaboram os entendimentos pré-construídos sobre os biomas brasileiros (Flávia-com-peixes), derrubar os exclusivismos espécies-territórios marcados por endemismos (Raymundo-com-morcegos) e elaborar políticas de uso da biodiversidade a partir de indicadores que consideram também o comportamento dos bichos (Raquel-com-insetos). Estaríamos diante de uma contradição que entende o animal nos confinamentos dos seus locais de origem e os humanos autorizados a se deslocarem pelos diversos territórios? Uma resposta apressada a essa questão seria menos interessante do que pensar sobre o que são as espécies, não em um fechamento - os biólogos com quem estabeleci interlocução afirmavam constantemente que uma espécie pode ser reinterpretada, podendo, inclusive, ser deslocada de um táxon para outro (a exemplo de Callistomys pictus) -, mas como dimensão categorial instável; sei que Donna Haraway é engajada neste trabalho (Gane; Haraway, 2010).

Biólogos e outros pesquisadores que contribuem com a circulação de discursos que indicam a pobreza da caatinga também devem ser contidos 
segundo meus interlocutores, porque esses "alóctones" (a ironia aqui é minha, e não dos biólogos da Uesb) não prestam atenção às especificidades do bioma e engendram artefatos para confirmar ideias pré-construídas e equivocadas sobre a caatinga. Falta-lhes a convivência duradora e atenta à sazonalidade necessária aos registros de indicadores da biodiversidade local. Esses biólogos não estariam envolvidos em processos para se tornarem "biólogos autóctones". Seria esse um dos problemas dos modelos explicativos da biodiversidade da caatinga que a tomam como bioma pobre em biodiversidade. Gostaria, ainda neste ponto, de deslocar a ideia de origem para a de adaptação, dispositivo que aprendi entre os biólogos, porque entendi que há um constante tornar-se biólogos quando esses profissionais operam deslocamentos territoriais e olham para animais dos lugares onde chegam, e não estou (nem os biólogos) negando esse tornar-se para os bichos, que também se deslocam, no mundo e na taxonomia, mas para as exigências espaçotemporais para tornar-se biólogos autóctones, que passam necessariamente por apreender algo que é oferecido pelos animais, quando estão em sintonia com eles (Despret, 2004, 2018) coabitando um mundo multiespécie (Haraway, 2011), nomeado de caatinga neste texto. Estou aqui olhando para a constituição dos biólogos na vinculação com animais dos territórios onde atuam. Para tentar contribuir com o debate e complexificar a tradução das pesquisas que envolvem animais, problematizo, nas próximas linhas, a localização do trabalho do biólogo entre a proteção da vida das espécies que seus apontamentos preservacionistas reivindicam e as mortes necessárias para produzir tais apontamentos, as circunstâncias nas quais biólogos e animais aliam-se em situações de morte (Despret, 2016), que são também produtoras de carreiras científicas e disciplinas científicas (ecologia e zoologia) situadas; o jogo ético de vida e morte é fundante desse movimento inventivo.

Um dia vi vários animais mortos em um tanque de um laboratório de zoologia e senti o cheiro do sangue misturado a cheiro de álcool. Durante a pesquisa, vi animais mortos de forma recorrente, mas nunca tinha ficado tão próximo do sangue como naquele dia. Eu já havia trabalhado com a morte quando fui servidor público em uma polícia científica, onde sentia o mesmo cheiro de sangue sistematicamente. Para alguns funcionários do setor em que me vinculava na polícia, o trabalho só acontecia se corpo sem vida aparecesse para ser interrogado. 
Os biólogos precisam também de um corpo sem vida para trabalhar, para interrogá-lo. Nas entrevistas, eles falavam da morte sem hesitar, evidenciando os detalhes dos seus modos de matar e rejeitando a ideia de sacrifício, enquanto os seus orientandos evitavam dizer a palavra "morte", deixando frases preenchidas por silêncios. Em uma determinada situação, um biólogo afirmou: "Eu mato! É claro que eu vou matar o bicho da melhor maneira. Eu não tenho o menor interesse que bicho nenhum sofra." Organizando animais mortos em uma coleção sobre a bancada do Labisa, uma estudante ponderou: "Infelizmente nós precisamos... [matar]", e um silêncio ocupou a cena e nos deixou desconcertados.

Entre os biólogos, (1) matam-se animais para tornar possível a aprendizagem do pesquisador iniciante, morte lamentada pelo iniciante, mas entendida como útil e necessária; e (2) matam-se animais para montagem de coleção de referência de laboratórios ou museus, morte nada ou pouco lamentada pelos pesquisadores experientes. As coleções de animais mortos (coleções de referência) são sistematicamente interrogadas pelos pesquisadores, que um dia também foram iniciantes e, portanto, mataram para aprender. $\mathrm{O}$ animal transformado em peça de coleção, o animal morto, é produto do encontro da morte lamentada e da morte nada ou pouco lamentada. Esses significados se encontram no recorrente retorno do animal, após a sua morte, em uma coleção. Ele, o defunto, atualiza a presença de um animal que, vinculado aos seus biólogos, vindica o direito de existir como parte da biodiversidade do planeta, circulando pelas diversas comunidades de prática das ciências biológicas. Trata-se de um encontro de sentidos sobre a morte e o matar para atualizar, senão eternizar, uma presença inquietante e questionadora. A morte, diria Despret (2016), torna os defuntos presentes de modos criativos, mobilizando os vivos a fazerem coisas (a agência não se encerra na morte). No contexto de trabalho dos biólogos, os animais mortos mobilizam, dentre outras coisas, os humanos a proteger as existências das suas espécies em tempos de extinção. Diferentemente de pesquisa no campo da saúde, em que se matam animais com a justificativa de produzir dados que colaborem com a saúde dos humanos, conforme têm demonstrado trabalhos como os de Souza (2017a; 2017b), nas ciências biológicas, mata-se para descrever indicadores que possam circular em discursos que têm como cerne a preservação de animais não humanos com preocupações éticas que refletem os vínculos afetivos entre biólogos e animais de pesquisa. Vidas de roedores, peixes, abelhas e vespas importam e a morte é um necessário 
caminho para investir em ações de descrição e proteção de espécies. Mata-se, gerando um sofrimento mínimo e necessário, para não tornar matável, ${ }_{1}^{14}$ tendo como consequência um possível manejo da biodiversidade que supere a objetificação e opressão dos animais, reconhecendo-os como trabalhadores de pesquisa, que respondem e não apenas reagem em interações com humanos (Derrida, 2011; Haraway, 2011; Souza, 2017b). É possível sintetizar o que ouvi e observei sobre morte na seguinte formulação: espécimes a matar para espécies proteger. É um trabalho com a morte para preservar vidas; aqui, para tornar os animais da caatinga não matáveis.

Ainda que qualquer vida tenha importância para os biólogos da caatinga, a empatia é seletiva e hierarquizada por meio de "parâmetros da biodiversidade", definindo as alteridades a serem preservadas. A empatia seletiva e hierarquizada apareceu no campo relacionada à ideia de "bicho com valor para biodiversidade", apresentada por Gilson. Coleções que apresentam animais mortos, que são melhor entendidos situando-os em seus habitats, seriam materiais que atestam o valor dos seus espécimes para biodiversidade, elas indicam registros de diversidade e ocorrência de animais que merecem proteção em políticas de preservação e manejo nos diversos territórios. Ratos e outros animais produzidos para fins de experimentação não têm a mesma sorte, seus nichos e habitats estariam circunscritos aos confinamentos físicos institucionais dos laboratórios.

Em consonância com Latour (2017), é possível afirmar que as coleções de referência, como inventários da morte, são partes das mediações que conectam a caatinga às comunidades de prática textual dos biólogos, dentre as quais circulam os planos de manejo. Seus animais (deslocados, separados, classificados e etiquetados) permitem que biólogos interroguem uma fatia de um imenso universo de possibilidade composto por todos os seres de uma determinada área investigada. A distinção do biólogo se dá na seleção e transporte de traços caraterísticos da biodiversidade e depende dos seus animais, das suas ciências (ecologia e zoologia, por exemplo) e das suas instituições (aqui, a Uesb).

14 Em Haraway (2011), o termo "matável" permite problematizar questões como indignidade moral e extermínio. Para ela, no entanto, grande parte da ciência animal não está interessada na espécie humana, mas está preocupada com a vida dos próprios animais. Assim, não é o matar (parte importante do trabalho dos biólogos) que leva ao "exterminismo", mas tonar os animais matáveis. 
Marcadas pelos coletivos da caatinga, ecologia e zoologia locais se deslocam nas redes das ciências biológicas. Para a caatinga se tornar reconhecível, precisa transformar-se em laboratórios (Latour, 2017) de ecologia e zoologia, em práticas situantes dos seus atores permeadas por tensões relacionadas a vida e morte. $\mathrm{O}$ trabalho produzido entre humanos e bichos faz emergir os entes da relação através da partilha de uma materialidade semiótica que inclui o sofrimento e o afeto, inerentes às relações instrumentais múltiplas e desiguais, que implicam, necessariamente, assimetrias (Haraway, 2011).

Entre vida e morte, situa-se também o trabalho do biólogo quando as suas pesquisas são alvos de contingenciamento ou corte de recursos, situações frequentes desde a fundação da Uesb na década de 1980 e tema recorrente nas entrevistas concedidas pelos biólogos. Impedidos de aparecerem como diferenças em indicadores ambientais, animais, biólogos e territórios ficam à mercê dos projetos desenvolvimentistas, a exemplo da extração de minério que identifiquei em distintos territórios da caatinga durante o trabalho de campo. Com poucos recursos financeiros para produzir apontamentos com potencial de preservação, os biólogos pesquisam usando reagentes (alguns deles com datas de validade expiradas) em laboratórios e matas, em situações de insalubridade e periculosidade, ${ }^{15}$ convivendo em um mesmo espaço com animais (vivos e mortos), aulas, protocolos de pesquisa e burocracias institucionais. Também os estudantes são expostos à insalubridade e à periculosidade desses espaços mistos e precisam aprender com seus professores, com seus pares e com os animais modos de existir e de se tornar biólogos. Em todo o período da pesquisa, não observei ações institucionais que promovessem formação de pesquisadores, iniciantes ou não, em biossegurança. Há exigências de comitês de ética em pesquisa, disciplinadas por legislações específicas sobre a matéria, mas há também pouca disponibilização de recursos financeiros e materiais que torne possível pesquisar os(com) animais da caatinga e, ao mesmo tempo, cuidar dos

15 No ordenamento jurídico do estado da Bahia, por força da lei ${ }^{\circ}$ 6.677, de 26 de setembro de 1994 (Bahia, 1994), há a previsão de recebimento de gratificações aos servidores que têm contato permanente com substâncias tóxicas ou em situações de risco de vida. Para receber as gratificações, os biólogos, professores das universidades estaduais que trabalham em condições perigosas e/ ou penosas nos termos da referida lei, precisam protocolar requerimentos que, inicialmente, tramitam em suas instituições de lotação e, posteriormente, são remetidos ao serviço médico do estado para avaliação dos pleitos. A tramitação pode demorar anos. Identifiquei um processo que tramitou pelo período de quatro anos para receber, finalmente, o deferimento. 
corpos dos biólogos e mitigar o sofrimento dos animais durante as suas mortes. As pesquisas que têm como alvo final a saúde dos humanos parecem receber, inclusive em situações de contingenciamento financeiro, mais recursos do que a pesquisa dos biólogos que visam à preservação das vidas dos não humanos, sejam eles endêmicos ou não. Configura-se assim o seguinte cenário: biólogos, mesmo em situações de insalubridade e periculosidade pouco assistidas pelas instituições em que trabalham, atuam para que os animais tenham chances de viver em mundos (worlding) menos ameaçadores para os não humanos, orientados por critérios da biodiversidade.

\section{Significando em vínculos}

Aqui, emoções são entendidas como parte dos agenciamentos que constroem relações, não como oposto da objetividade (Despret, 2004, 2011c, 2011d). Nessa direção, fiquei especialmente interessado pelas definições usadas pelos biólogos para marcar as suas vinculações aos animais: "amor", "amizade", "paixão" e "aprendizagem". Elas apareceram no campo de modo recorrente e apontavam para a subjetivação de espécimes e espécies de animais de pesquisa.

No Laboratório de Zoologia I, além da narrativa de paixão entre um besouro e um vertebradólogo (Gilson), ouvi: "Amo os peixes, adoro. Não consigo me imaginar trabalhando com outra coisa" (Flávia). No Labisa, o biólogo-ecólogo (Raymundo) que trabalha com morcegos disse que, toda vez que está em campo, abre a rede e captura um morcego, sente que reencontrou "um velho amigo". E acrescentou: "O morcego, ele é quase um filho." Raquel destacou ainda a possibilidade de aprender com os bichos:

[...] quanto mais você estuda biologia comportamental desses bichos, dos insetos, e você vê como eles exploram os recursos, como eles dependem dos recursos naturais para a sobrevivência, como eles fazem escolhas que sempre focam o sucesso do indivíduo e da espécie, da reprodução, para que todo mundo se dê bem, você aprende, na verdade, a simplificar as suas decisões. Então, muitas vezes, em vez de complicar, eu simplifico. Eu digo: "Gente, eu estou em busca de recursos, os recursos têm que ser utilizados da maneira mais eficiente possível e as minhas escolhas, elas devem refletir uma eficiência biológica." Eu 
simplifiquei muito a minha vida quando eu comecei a pensar desse jeito. [...] O inseto não desperdiça recurso, ele não desperdiça tempo. A gente aprende, fica um pouquinho mais generoso com relação ao outro, mais honesto e mais simples! Isso foi o que eu aprendi com as abelhas e as vespas.

Como no enredamento de primatas com humanos descrito por Sá (2010), animais, aqui abelhas, vespas, roedores, peixes e morcegos, promoveram a humanidade dos biólogos. Portanto, não se trata de metaforizar comportamentos dos não humanos ou de projetar a humanidade dos biólogos sobre os animais de pesquisa, mas de promover as alteridades (humanas ou não) agregadas nos coletivos relacionais de pesquisa, explicitando o caráter híbrido dos coletivos dos laboratórios de ecologia e zoologia, que, diria Haraway (2011), vão além de hierarquias taxonômicas e exigem forte sensibilidade não antropomórfica, atenta a diferenças irredutíveis, fazendo aparecer o florescimento multiespécie.

Para Despret (2004, 2016), a empatia transforma o sujeito empático, mas não habilita o outro com o qual ele se relaciona como sujeito, pois, para que este assim apareça, o seu ponto de vista precisa ser ativado, e isso só acontece quando os atores da relação sintonizam, criando laços que permitem contar histórias e estabelecer vínculos. Vínculos que, nos contextos observados no trabalho de campo que transitam por este texto, permitiram que os biólogos se tornassem - tornar-se com, nos tempos de Despret (2016) - vertebradólogos, ictiólogos, ecólogos e entomólogos com animais aliados, que se tornaram (tornar-se juntos) roedores, peixes, morcegos, abelhas e vespas. Ao olharem entre si, animais (os espécimes e a sua generalização em espécies, animais generalizados) e biólogos sintonizam-se em práticas experimentais e são transformados em relações de afetos-trabalhos. As coleções de referências seriam ainda inventários desses vínculos, como nossos cadernos de campo que também inventariam as relações que tecemos com nossos interlocutores, muitas vezes silenciadas nos textos publicados.

Não nos esqueçamos que a adesão dos animais a uma pesquisa tem a ver com os dispositivos experimentais mobilizados (Despret, 2011a). Nesses termos, os laboratórios de ecologia e zoologia deste texto, onde trabalham animais não humanos e biólogos, só podem ser entendidos como práticas situantes que produzem saberes sobre a caatinga que se deslocam por redes 
constituídas pelas comunidades de prática das ciências biológicas, conectando local e global (Latour, 2017). Esses saberes locais permitem contar outras histórias (Despret, 2016), como aquelas dos animais que participam da formulação do nacional, nação rica em biodiversidade. Por isso, é sempre muito chocante, e contraditório, quando humanos que se dizem "patriotas" agem para apagar as materialidades dos biomas brasileiros como potenciais latentes para sustentar a ideia de nação, autorizando a exploração de florestas compostas por espécies exclusivas, por ora. As histórias contadas pelos biólogos propõem outros engajamentos, focados em políticas de preservação que propõem prestar atenção nos bichos, ativando os seus pontos de vista e apostando que eles têm, como os seus humanos, intenção e elaboram significações (Despret, 2016); são Outros significantes (Haraway, 2011) que merecem viver, sem terem que comprovar capacidade de sentir (senciência) ou superioridade em relação aos demais viventes, e não recursos a serem apropriados, explorados e ou dizimados. Práticas científicas na caatinga vinculam biólogos e animais em coexistências, transformando as relações que os articulam, são relações de "antropo-zoo-gênese" (Despret, 2004).

Talvez, ao nomear as relações com bichos (mortos ou vivos) com marcadores que explicitam afeto e aprendizagem, os biólogos estejam agindo também para ampliar os carismas dos animais, mesmo aqueles como sapos e morcegos, que têm a dignidade negada pelos militantes dos movimentos de liberação animal (Descola, 1998), distantes filogeneticamente dos humanos e pouco carismáticos entre os humanos não biólogos, para redes de conservação da biodiversidade com chances de tornar concretas as diretrizes dos planos de manejo. Biossegurança, se quisermos levar adiante o apelo preservacionista das pesquisas dos biólogos, apontam para ações que buscam garantir a proteção das existências das diversas espécies de animais às quais se vinculam em coletivos multiespécies e a segurança ambiental dos seus entornos.

Na esteira de Haraway (2011), entendo que, ao comungarem das condições de trabalho e sofrimento com os animais de pesquisa, biólogos, mesmo tendo conhecimento das negligências institucionais para mitigar danos aos atores envolvidos, assumem as solidariedades e os riscos implicados, compartilham cuidado e dor no cotidiano prosaico e consequente das suas práticas através das quais passam a existir como parte da caatinga nas disciplinas ecologia e zoologia. 


\section{Considerações finais}

Eu trabalho com inseto, com abelha e com vespa, eu encontro evidências biológicas que me fazem refletir sobre a espécie humana, se nós estamos fazendo o melhor uso dos nossos recursos como fazem os insetos. (Raquel).

Os apontamentos do trabalho de campo e as análises etnográficas mobilizados neste texto tornam possível afirmar que animais não humanos são bons para trabalhar juntos como parceiros de descrições da biodiversidade, pois colaboram com a elaboração da caatinga em indicadores de diversidade e ocorrência nas disciplinas científicas ecologia e zoologia. Traduzidos em laboratórios e museus, animais e biólogos circulam como diferenças em comunidades de prática (textuais e outras), informando a composição dos territórios que pesquisam e se firmando como testemunhas de um mundo sempre ameaçado pelos humanos.

Nessa chave analítica, animal, território e biólogos (singularidades compostas por multidões de outros entes) podem ser sempre outras coisas quando estão atuando em um mesmo coletivo multiespécie, em um mesmo campo de relação na caatinga no qual as equivalências entre humanos e não humanos fazem aparecer relações de aprendizagem, amor, amizade e paixão. Roedores, peixes, morcegos, abelhas, vespas e seus biólogos, ao cruzarem seus olhares em contextos de pesquisa, tornam-se agentes que fazem a caatinga como bioma exclusivamente brasileiro a ser preservado e, com isso, fazem também a ecologia e a zoologia locais como saberes de caatinga que sustentam a necessidade das ciências biológicas e dos seus atores em territórios da Bahia. As descrições produzidas nesses cruzamentos humano-animal circulam internacionalmente em comunidades de prática das ciências biológicas e, com elas, a caatinga (e as caatingas) e os animais que a(s) habitam. Em síntese, poderíamos dizer que animais e biólogos vinculam-se em formas híbridas de existência.

Ao problematizar estudos conduzidos com animais, Despret (2011b, p. 71) questiona se os animais seriam um bom modelo para os seres humanos. Sua reposta é positiva: sim, seriam em certas condições. Ratos, macacos e outros animais, aqui roedores, peixes, morcegos, abelhas e vespas, nos ensinariam, segundo ela, "uma grande quantidade de coisas sobre nós mesmos". Para isso, os humanos pesquisadores, como os biólogos, não devem negligenciar o que respondem os animais em contextos de pesquisas. 
Não posso concluir sem antes fazer referência aos conflitos de interesse entre poder público, biólogos, ativistas ambientais, ruralistas e outros humanos em torno das disputas pelas políticas de manejo da caatinga, bioma loteado por propriedades de ruralistas que estão também nas assembleias legislativas compondo as "bancadas do boi". Nesses conflitos, os "donos do boi" parecem sair sempre ganhando e talvez isso explique por que a caatinga não tenha sido até hoje reconhecida como patrimônio nacional pela Constituição Federal (Brasil, 1988).

\section{Referências}

BAHIA. Casa Civil. Lei $n^{0}$ 6.677, de 26 de setembro de 1994. Dispõe sobre o Estatuto dos Servidores Públicos Civis do Estado da Bahia, das autarquias e das fundações públicas estaduais. Salvador, 1994. Disponível em: http://www.legislabahia.ba.gov. br/documentos/lei-no-6677-de-26-de-setembro-de-1994. Acesso em: 10 maio 2019.

BRASIL. Constituição Federal do Brasil. Brasília: Senado Federal, 1988.

BRASIL. Presidência da República. Casa Civil. Subchefia para Assuntos Jurídicos. Lei $n^{\circ}$ 9.985, de 18 de julho de 2000. Regulamenta o art. 225, $\$ 1^{\circ}$, incisos I, II, III e VII da Constituição Federal, institui o Sistema Nacional de Unidades de Conservação da Natureza e dá outras providências. Brasília, 2000. Disponível em: http://www.planalto.gov.br/ccivil_03/leis/19985.htm. Acesso em: 10 maio 2019.

DERRIDA, J. O animal que logo sou. São Paulo: Editora da Unesp, 2011.

DESCOLA, P. Estrutura ou sentimento: a relação com o animal na Amazônia. Mana, Rio de Janeiro, v. 4, n. 1, p. 23-45, abr. 1998.

DESPRET, V. The body we care for: figures of anthropo-zoo-genesis. Body \& Society, v. 10, n. 2-3, p. 111-134, June 2004.

DESPRET, V. Os dispositivos experimentais. Fractal: Revista de Psicologia, Rio de Janeiro, v. 23, n. 1, p. 43-58, apr. 2011a.

DESPRET, V. O que as ciências da etologia e da primatologia nos ensinam sobre as práticas científicas?. Fractal: Revista de Psicologia, Rio de Janeiro, v. 23, n. 1, p. 59-72, abr. 2011b.

DESPRET, V. As ciências da emoção estão impregnadas de política? Catherine Lutz e a questão do gênero das emoções. Fractal: Revista de Psicologia, Rio de Janeiro, v. 23, n. 1, p. 29-42, abr. 2011c. 
DESPRET, V. Leitura etnopsicológica do segredo. Fractal: Revista de Psicologia, Rio de Janeiro, v. 23, n. 1, p. 5-28, abr. 2011d.

DESPRET, V. O que diriam os animais se... Belo Horizonte: Chão de Feira, 2016. (Cadernos de Leituras n. 45).

DESPRET, V. ¿Qué dirían los animales... si les hiciéramos las preguntas correctas?. Buenos Aires: Cactus, 2018.

FAVRET-SAADA, J. Ser afetado. Tradução de Paula Siqueira. Cadernos de Campo, v. 13, n. 13, p. 155-161, 30 mar. 2005.

GANE, N.; HARAWAY, D. Se nós nunca fomos humanos, o que fazer?. PontoUrbe, v. 4, n. 6, p. 1-22, jul. 2010.

GASPAR, S. dos S. Cães e gatos como pacientes: uma etnografia de um hospital veterinário. 2018. Tese (Doutorado em Antropologia Social) - Museu Nacional, Universidade Federal do Rio de Janeiro, Rio de Janeiro, 2018.

HARAWAY, D. A partilha do sofrimento: relações instrumentais entre animais de laboratório e sua gente. Horizontes Antropológicos, Porto Alegre, ano 17, n. 35, p. 27-64, jan./jun. 2011.

INGOLD, T. Humanidade e animalidade. Revista Brasileira de Ciências Sociais, v. 10, n. 28, p. 39-53, 1995.

INGOLD, T. Estar vivo: ensaios sobre movimento, conhecimento e descrição. Petrópolis: Vozes, 2015.

INSTITUTO CHICO MENDES DE CONSERVAÇÃO DA BIODIVERSIDADE. Livro vermelho da fauna brasileira ameaçada de extinção: volume I/1. Brasília, 2018.

KIRKSEY, S. E.; HELMREICH, S. The emergence of multispecies ethnography. Cultural Anthropology, v. 25, n. 4, p. 545-576, 2010.

LATOUR, B. Reagregando o social: uma introdução à teoria do ator-rede. Salvador: Edufba: Edusc, 2012.

LATOUR, B. A esperança de Pandora: ensaios sobre a realidade dos estudos científicos. São Paulo: Editora da Unesp, 2017.

MERLEAU-PONTY, M. A linguagem indireta. In: MERLEAU-PONTY, M. A prosa do mundo. São Paulo: Cosac Naif, 2012. p. 93-121.

NASCIMENTO, A. L. da C. P.; FERREIRA, J. D. C.; MOURA, G. J. B. de. Marsupiais de uma área de caatinga (Pernambuco, Brasil) com registro de nova localidade para Caluromys philander (Linnaeus, 1758). Revista Ibero Americana de Ciências Ambientais, Aquidabã, v. 4, n. 1, dez. 2012/maio 2013. 
OSÓRIO, A. Compaixão, moral e sofrimento animal entre protetores de gatos de rua. Iluminuras, v. 17, n. 42, p. 51-82, 2016.

SÁ, G. J. S. e. "Meus macacos são vocês": um antropólogo seguindo primatólogos em campo. Revista AntHropológicas, v. 16, n. 2, p. 41-66, 2005.

SÁ, G. J. S. e. "Abraços de mono": elos perdidos e encontros intersubjetivos em etnografia com primatólogos no Brasil. Mana, Rio de Janeiro, v. 16, n. 1, p. 179-211, abr. 2010.

SÁ, G. J. S. e. “Afinal, você é um homem ou é um rato?”. Campos: Revista de Antropologia, v. 14, n. 1/2, dez. 2013.

SCHOBER, J. Preservação e uso racional do único bioma exclusivamente nacional. Ciência e Cultura, São Paulo, v. 54, n. 2, p. 6-7, out. 2002.

SEGATA, J. Quando o animal dura mais que a estimação. Mana, Rio de Janeiro, v. 22, n. 3, p. 831-856, dez. 2016.

SEGATA, J. O Aedes aegypti e o digital. Horizontes Antropológicos, Porto Alegre, ano 23, n. 48, p. 19-48, maio/ago. 2017.

SOUZA, I. M. de A. Corpos comensuráveis: produção de modelos animais nas ciências biomédicas. Horizontes Antropológicos, Porto Alegre, ano 23, n. 48, p. 275-302, maio/ago. 2017a.

SOUZA, I. M. de A. Afeto entre humanos e animais não humanos no biotério. Revista Brasileira de Ciências Sociais, São Paulo, v. 32, n. 94, e329407, 2017b.

SÜSSEKIND, F. A onça pintada e o gado branco. Anuário Antropológico 2011/II, p. 111$134,2012$.

SÜSSEKIND, F. Sobre a vida multiespécie. Revista do Instituto de Estudos Brasileiros, n. 69, p. 159-178, abr. 2018.

TSING, A. Margens indomáveis: cogumelos como espécies companheiras. Tradução Pedro Castelo Branco Silveira. Ilha: Revista de Antropologia, v. 17, n. 1, p. 177-201, 2015.

TSING, A. Viver nas ruínas: paisagens multiespécies no Antropoceno. Brasília: IEB Mil Folhas, 2019.

VANDER VELDEN, F. F. V. Sobre cães e índios: domesticidade, classificação zoológica e relação humano-animal entre os Karitiana. Avá: Revista de Antropología, n. 15, p. 125-143, jul. 2009.

Recebido: 30/06/2019 Aceito:14/11/2019 | Received:6/30/2019 Accepted:11/14/2019 